\title{
INVESTIGAÇÕES ESTRUTURAIS DE UM DIQUE MÁFICO CAULINIZADO NA SERRA DO ESPINHAÇO MERIDIONAL, UTILIZANDO O GPR
}

\author{
Paulo Roberto Antunes Aranha1 \& Adolf Heinrich Horn ${ }^{2}$
}

\begin{abstract}
The present work continues with the investigation of an intemperized and kaolinized intrusive mafic body. This body is localized south of Diamantina near the "Serra da Galinha". These dike intruded units of the Rio Paraúna (Bandeirinha Formation) and Espinhaço (Guinda Group) super groups.

New field data are presented obtained by GPR and compared with borehole informations. Using these new data and informations from literature it is able to give the form and the delimitations of the dike more exactly and describe the genesis of the kaolin, too.
\end{abstract}

\section{OBJETIVOS}

O principal objetivo desta investigação foi mostrar novos aspectos desta ocorrência muito peculiar de caulim em um dique máfico além dos resultados publicados por Sgarbi \& Horn (1992).

Outro objetivo foi testar a utilização do radar na identificação de diques, verificar a aplicabilidade e resolução do método para problemas de depósitos supergênicos. Na literatura disponível não se encontra nenhuma pesquisa desta natureza, apenas o trabalho de Porsani (1999) sobre a identificação de um diabásio encaixado em arenitos, contudo sem caracterizar o seu contorno e o interior do mesmo. Assim este trabalho tem um caráter pioneiro neste tipo de investigação, com a utilização do GPR.

\section{INTRODUÇÃO}

\section{Investigações anteriores}

As primeiras referências petrológicas na literatura geológica sobre metabasitos intrusivos no Supergrupo Espinhaço e as seqüências mais antigas devem-se a Guimarães (1933). Grossi-Sad \& Vaz-de-Melo (1969) descreveram a evolução intempérica desses metabasitos, a qual originou acumulações importantes de bauxita na região. Uhlein (1982) apresentando uma compilação sobre a ocorrência de metabásicas na Serra do Espinhaço Meridional, destaca a ocorrência de bauxita, relacionada com a alteração intempérica desses corpos intrusivos.

Schöll \& Fogaça (1981) descreveram diques e soleiras de dioritos, gabros e diabásios, incipientemente metamorfizados, os quais geraram, por intemperismo, ocorrências localizadas de caulim, mencionando especificamente o corpo caulinitizado ora investigado.

A gênese e o processo intempérico atuante neste corpo caulinizado foi investigado com mais detalhes por Sgarbi \& Horn (1992) e Horn \& Sgarbi (1994).

\section{Condicionamento geológico}

Diques, sills e "stocks" de natureza básica intrudiram grande parte das seqüências arqueanas e mesoproterozóicas da região de Diamantina, mas são notavelmente expressivos nos metassedimentos do Supergrupo Espinhaço, com destacada concentração nas unidades mais antigas: formações São João da Chapada e Sopa-Brumadinho (figura 1).

Os diques podem atingir comprimentos de 10-20 $\mathrm{km}$ e suas espessuras variam em torno de dezenas de metros. Nem sempre os corpos são contínuos ao longo das falhas, às vezes bifurcam-se, desaparecem ou mesmo sofrem espessamento em locais de cruzamento de duas ou mais falhas. A direção preferencial é $\mathrm{N} 50^{\circ}-70^{\circ} \mathrm{W}$, contudo direções $\mathrm{N}-\mathrm{S}, \pm$ paralelas às estruturas regionais do Supergrupo Espinhaço podem ser observadas na área de São João da Chapada. Vários "stocks" de dimensões variadas (até $10 \mathrm{~km}^{2}$ ) são encontrados nas vizinhanças. Os "sills" constituem ocorrências bastante raras (COMIG, 1997).

Todas estas intrusivas básicas tem algumas propriedades em comum:

a. constituição mineralógica relativamente constante para rochas originalmente gabróicas e diabásicas;

b. quando não são inteiramente transformadas pelo intemperismo químico, exibem núcleos e massas sem qualquer deformação aparente (com vestígios de textura original ofítica e subofítica;

c. sempre ocorrem transformações metamórficas (retrógradas) posteriores a intrusão e relacionadas aos eventos tectono-metamórficos pós-Espinhaço, provavelmente no Ciclo Brasiliano;

d. as idades concentram-se em torno de 1.000 a $900 \mathrm{Ma}$ (COMIG, 1997);

e. a granulação aumenta gradativamente da margem dos corpos para o núcleo.

Os metabasitos são de granulação média, coloração 


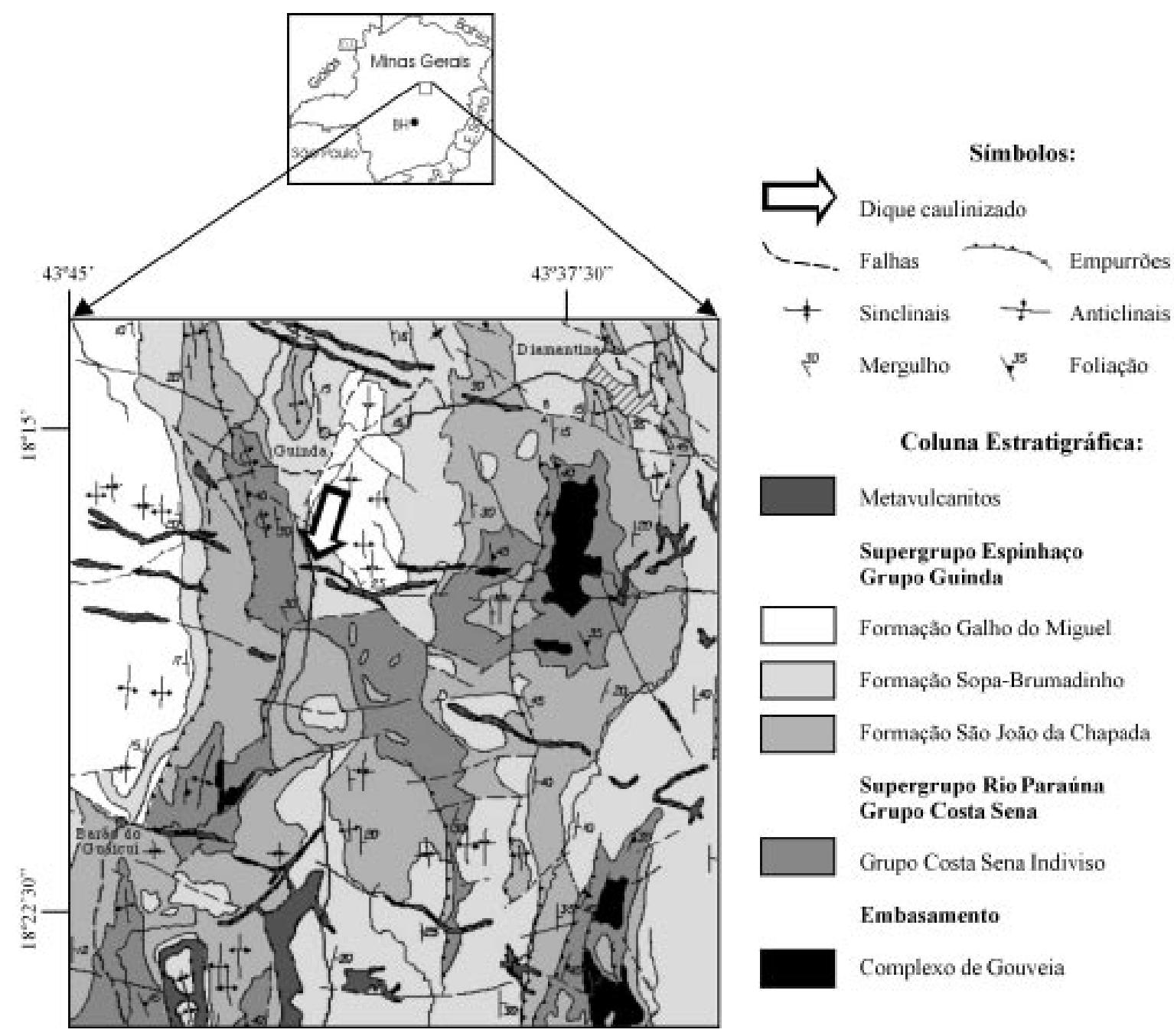

Figura 1: Mapa geológico e de localização da área (segundo COMIG 1997; modificado). O dique máfico é indicado.

Figure 1: Geological e location map (after COMIG 1997; modified). The mafic dike is indicated.

verde acinzentado ou verde escuro a cinza-esverdeado, dependendo do grau de alteração. A atuação de processos metamórficos posteriores nessas rochas estão indicados pelas transformações mineralógicas.

Nos diques mais espessos, faixas centimétricas a métricas com foliação incipiente acham-se restritas às suas bordas. Essa foliação é possivelmente resultante de movimentos cisalhantes durante ou após o posicionamento do magma básico. A falta de xenólitos talvez indique a não ocorrência de brechação violenta durante o processo intrusivo, sugerindo um ambiente de relaxamento.

\section{A intrusão investigada}

Esta intrusão situa-se a oeste do km 116 da BR-367 (Curvelo-Diamantina) e ocorre na forma de dique que corta unidades proterozóicas representadas pelos supergrupos Rio Paraúna e Espinhaço, ambos predominantemente quartzíticos (Schöll \& Fogaça, 1981).

A caulinização diminui, de oeste para a leste, onde predomina a lateritização do conjunto, especialmente onde este aflora cortando unidades da Formação Sopa-
Brumadinho.

O dique estende-se por cerca de $1.000 \mathrm{~m}$ na direção aproximada leste-oeste. Esta intrusão acompanha um falhamento situado $100 \mathrm{~m}$ ao sul, é cortada transversalmente por fraturas (N-S), cujos planos encontram-se às vezes enriquecidos em sericita, quartzo e outros minerais secundários, como também óxidos/ hidróxidos de $\mathrm{Mn}$ e Fe.

Os limites oeste e leste são representados por falhas de empurrão, recobertas a leste por material coluvionar, a oeste é superposto pelas unidades da Formação SopaBrumadinho e seus produtos de imtemperismo. As espessuras dos diques variam entre 1 e $20 \mathrm{~m}$, (Figura 2), seguem direção N75W e apresentam mergulho subvertical.

Devido à distribuição mineralógica dos minerais secundários em sua composição o dique foi subdividido na direção E-W em três partes [corpos I, II (Sgarbi \& Horn 1992); e III] (figura 3). Os corpos exibem zoneamento difuso e sub-paralelo à sua maior extensão. Em cada corpo a composição mineralógica é relativamente constante, predominando minerais secundários como anfibólios da série tremolita- 


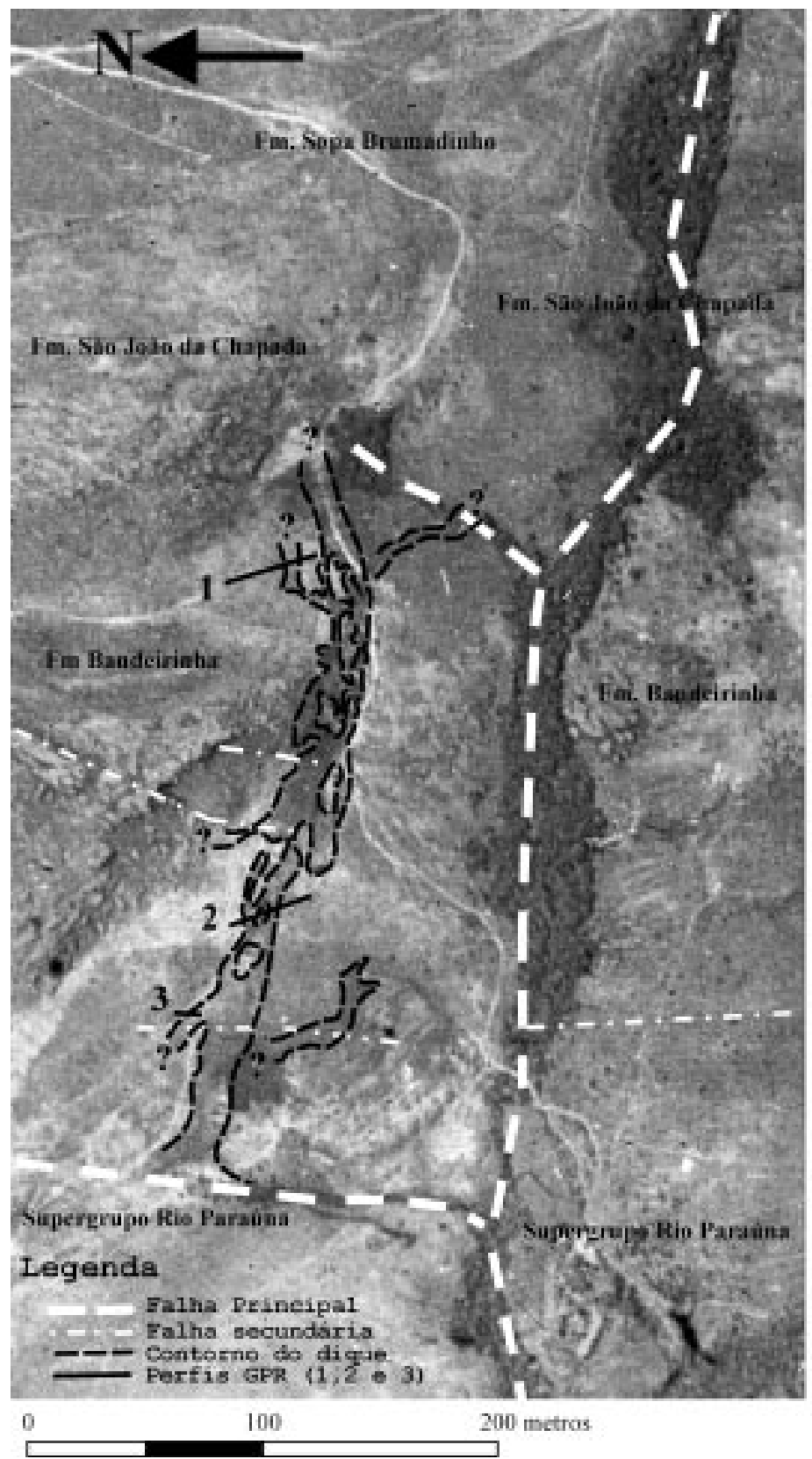

Figura 2: Fotografia aérea com a situação geológica do dique e indicação dos perfis executados com GPR. Esc. 1:25.000.

Figure 2: Aerial photography with the geological situation. The profiles executed by GPR are indicated. Scale: 1:25.000

actinolita (uralitização dos piroxênios) e de epidoto/ cliniozoesita (alteração do feldspato cálcico). Esses minerais ocorrem com concentrações diferentes em cada corpo. Associados aos minerais secundários ocorrem leucoxênio (núcleos de ilmenita e clorita), albita neoformada, quartzo, biotita e apatita. Sgarbi \& Horn (1992) verificaram que além destes minerais, ocorre também a presença de titanita e sulfetos de cobre, e ainda foram observados cristais de pirita e/ou calcopirita.

A natureza composicional da intrusão pode ser inferida em função do contato geológico regional (figura 2), como também pela presença de estruturas relíticas da rocha básica; localmente observadas em material retirado de profundidades maiores (acima de $8-10 \mathrm{~m}$; figura 4).

O corpo I exibe os limites sul enriquecidos em hidróxidos de ferro, com a coloração vermelha afetando também os quartzitos encaixantes. Na interface caulimquartzito, ocorrem veios subverticais de quartzo, preenchendo fraturas, com espessuras de até $0,5 \mathrm{~m}$, ricos em impurezas ferruginosas. Os limites norte deste corpo exibem caulim mais puro e branco e tem contatos bruscos com o quartzito, com bolsões do material do dique entrando em fraturas do quartzito. Veios de quartzo ocorrem também aqui, mas em menor espessura. O quartzito encaixante, localizado ao sul e a leste do corpo I, possui um nível filítico (verde) com cerca de $0,8 \mathrm{~m}$ de espessura, contendo bolsões de quartzo, filões de caulim e sericita, que apresenta acamamento (N55W/ 


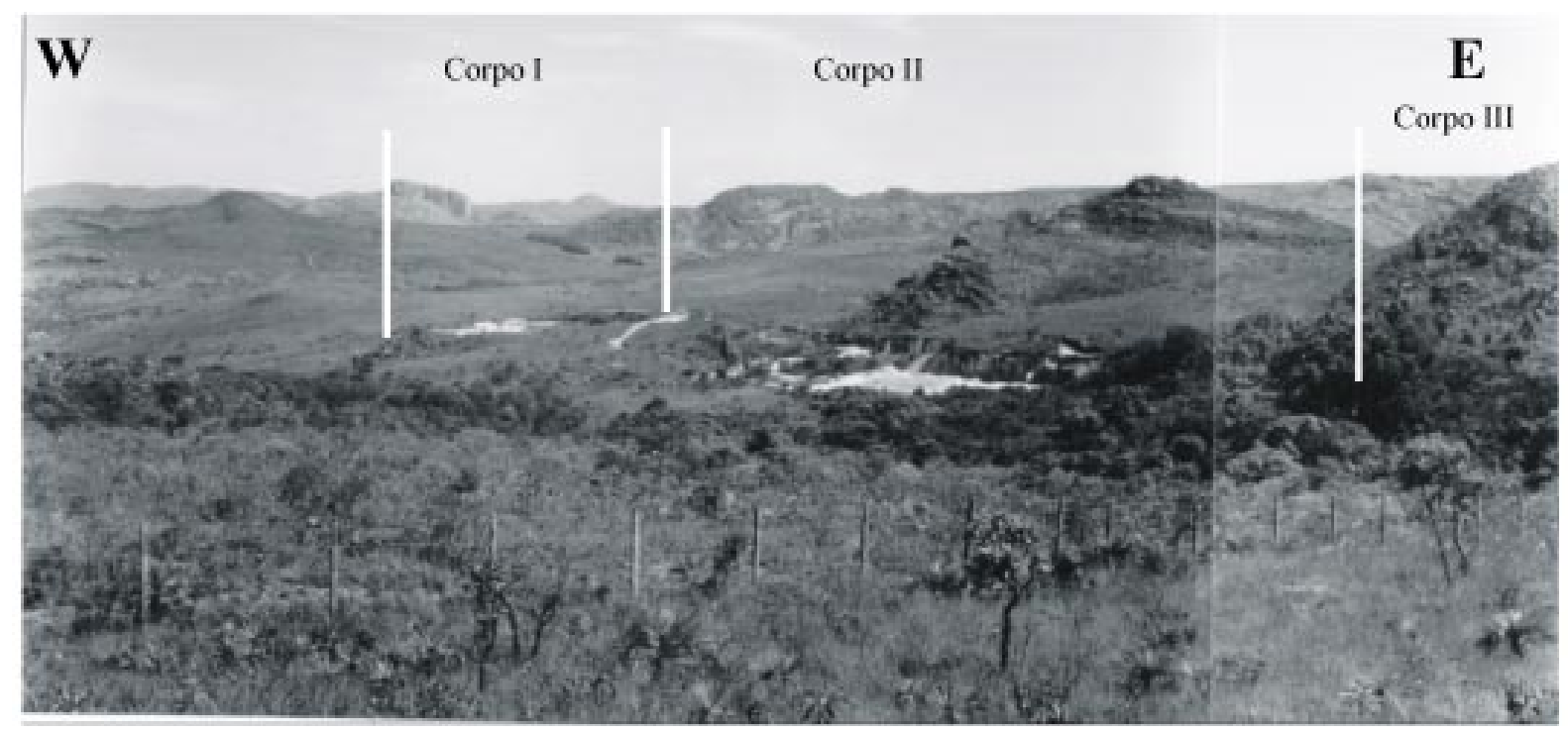

Figura 3: Fotografia do dique máfico. Direção da observação é do sul para norte. Os três corpos (I, II, II) são separados.

Figure 3: Photography of the mafic dike. The direction of observation is from the south. The three corps (I, II, II) are separated.

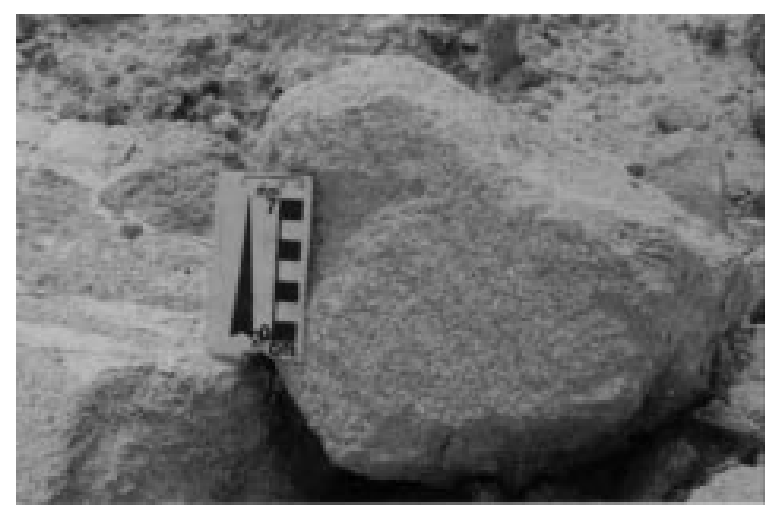

Figura 4: Fotografia da rocha intemperizada. A estrutura primária ainda é preservada e visivel.

Figure 4: Photography of the intemperized rock. The primary structure is still preserved and visible.

$50 \mathrm{NE}$ ), que é concordante com a direção de acamamento do quartzito. Investigações petrográficas mostraram que se trata de uma turmalina sericita-filito (Nível E da Formação Sopa-Brumadinho). Este filito, por razões químicas, não pode ser o protólito do caulim ora investigado (Horn \& Sgarbi 1994).

O corpo II apresenta as regiões dos seus limites norte e sul enriquecidos em hidróxidos de ferro e contém uma zona central ampla com caulim puro, misturado com sericita. Nestas partes, nota-se um leve decréscimo da granulometria do centro para as bordas do corpo.

O corpo III tem a mesma aparência como a maioria dos diques da Serra do Espinhaço Meridional. Ele é altamente laterizado, ocorrendo manchas e camadas de óxidos de Fe e Mn nos quartzitos encaixantes. Devido ao profundo intemperismo e a pouca produção nos trabalhos de lavra, o corpo aflora somente em alguns lugares.

Nos corpos I e II, as partes mais avermelhadas (mais profundos) contêm zonas de cor ocre-carmim com textura granoblástica (inequigranular)e granulação média, sugerindo tratar-se de uma rocha básica alterada (figura 4).

A cobertura coluvionar parcial apresenta espessura variando entre 0,5 e $1,5 \mathrm{~m}$ e é formado por uma mistura de areia quartzosa, argila preta e material orgânico (turfa; plantas etc.), o que propiciou a condição para a geração de ácidos que alteraram o material primário da intrusão, sendo desse modo a razão para a ocorrência do caulim puro. O contato entre o colúvio e o caulim é gradacional, com uma fração argilosa cinza sobrepondose ao caulim branco(Sgarbi \& Horn, 1992; figura 5).

\section{LEVANTAMENTO GEOFÍSICO}

O método geofísico escolhido para a investigação dos diques foi o método eletromagnético GPR (Ground Penetrating Radar). O GPR vem sendo aplicado em diversas áreas das geociências (BENSON, 1995; DAVIS \& ANNAN, 1989; HARA \& SAKAYAMA, 1985; HUGGENBERGER et al., 1994). Em Minas Gerais tem sido aplicado no estudo de coberturas superficiais na região de Gouveia (NEVES et al., 1997; ARANHA et al., 1998; HORN et al., 1998). Na literatura disponível não se encontra nenhuma pesquisa desta natureza. Assim este trabalho tem um caráter pioneiro neste tipo de investigação com a utilização do GPR.

Para isto utilizou-se um GPR que permite uma investigação, neste caso até $20 \mathrm{~m}$, e assim bem abaixo do nível da caulinização onde se encontra, provavelmente, ainda rocha sã. Isto junto com informações da empresa exploradora (Perez, 2001; com. Verb.) permitiu uma investigação da subsuperfície, procurando delimitar os contatos da rocha emcaixante com o dique, as carateristicas internas do conjunto, como também a identificação dos contatos caulim/laterito/rocha "não alterada". 


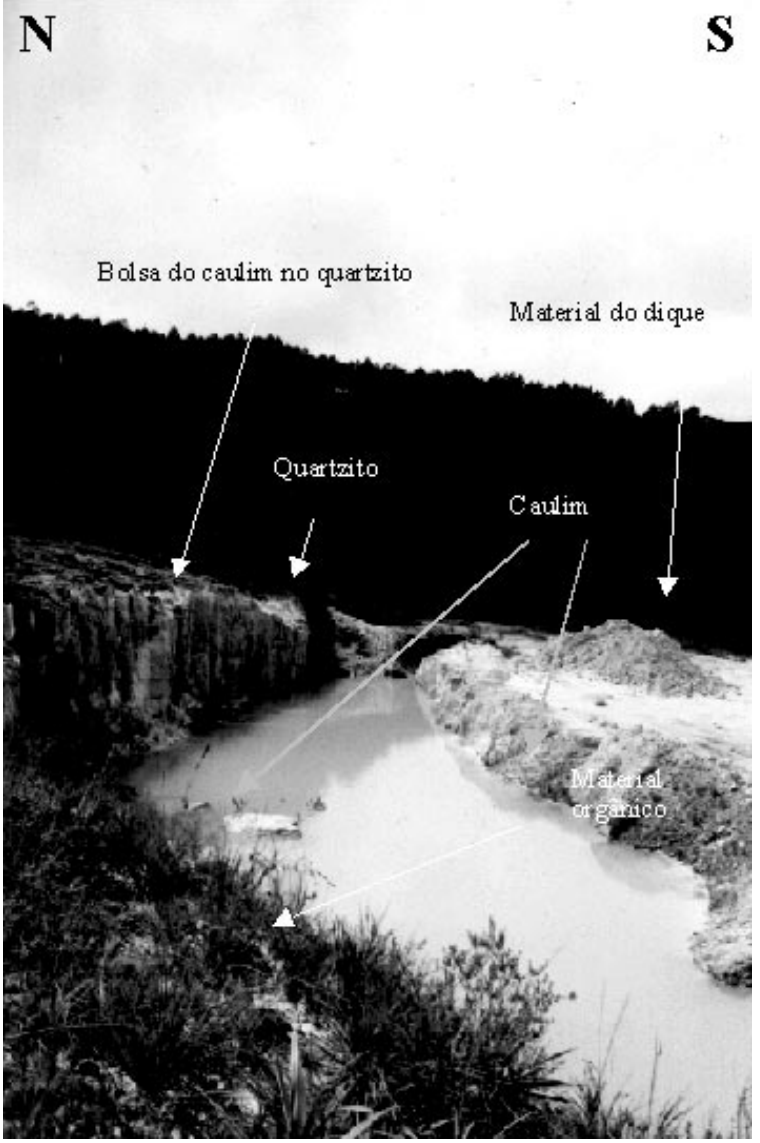

Figura 5: A figura mostra a parte central do dique, olhando do oeste para o leste.

Figure 5: The figure shows the middle part of the intrusion, looking vom east to west.

A técnica GPR é similar, em princípio, à sísmica de reflexão. O GPR emite ondas de rádio de 10 a 1.000 $\mathrm{MHz}$, no solo para detectar as reflexões do sinal e a partir destes dados inferir a estruturação do subsolo. $\mathrm{O}$ campo EM (eletromagnético) que varia no tempo, consiste do acoplamento dos campos elétrico (E) e magnético (H). O modo com que o campo EM interage com os materiais naturais controla o espalhamento e a atenuação do mesmo no solo/rocha.

$\mathrm{O}$ equipamento de radar consiste de quatro elementos principais, a unidade de transmissão, a unidade de recepção, a unidade de controle e a unidade de visualização. $O$ transmissor produz um pulso de alta voltagem com mínima duração e irridiada pela antena transmissora para o solo/rocha. O sinal transmitido se propaga no solo/rocha e os sinais refletidos são detectados na volta pela antena receptora e repassados para o sistema de recepção. Este sistema amplifica o sinal e o adequa para ser visualizado.

Como a propagação do sinal depende das propriedades dielétricas do solo/rocha que são primariamente controladas pelo seu conteúdo de água, o radar, então, é sensível às variações de composição (ph, viscosidade, temperatura, etc.) dos fluidos intersticiais das rochas e às mudanças estruturais destas, preenchidas ou não com água.
Os perfis de radar foram executados no modo "stock" ao longo de linhas, utilizando o equipamento da Ramac-MalaGeoscience. Os espaçamentos entre os pontos amostrados foram de $0,25 \mathrm{~m}$ utilizando as antenas de $100 \mathrm{MHz}$, e de $0,10 \mathrm{~m}$ com a antena de 200 MHz. A separação entre as antenas foi de $1,0 \mathrm{~m}$ e de $0,6 \mathrm{~m}$ para as antenas de $100 \mathrm{MHz}$ e $200 \mathrm{MHz}$, respectivamente. Para a obtenção da velocidade da onda EM no subsolo, obteve-se perfis CMP (common mid point) em cada linha executada. As velocidades médias encontradas foram de $110 \mathrm{~m} / \mu$ s para o quarzito, e de $75 \mathrm{~m} /$ ìs para o dique.

Neste estudo foi executado o processamento padrão básico:

- Dewow: remoção de ruídos EM instrumentais e aleatórios, de baixa freqüência;

- Tempo de início: marcar na seção o tempo de início da seção de radar, "tempo zero";

- Filtragem: utilização do filtro do tipo gaussiano, com freqüência central de $100 \mathrm{MHz}$ e $200 \mathrm{MHz}$, para cada tipo de antena utilizada;

- Correção topográfica: correção da topografia da linha executada;

Conversão em profundidade: transformar a seção de campo obtida em tempo, em seção em profundidade, utilizando as velocidades obtidas nas CMP's.

\section{RESULTADOS OBTIDOS}

A região do dique foi investigada em três perfis localizados nas linhas 1, 2 e 3 (figura 2), o que permitiu a avaliação do seu comportamento geométrico para a profundidade, como também uma avaliação do grau do intemperismo, especialmente da caulinização. Foram utilizados, neste contexto, também as investigações feitas e publicadas por Sgarbi \& Horn (1992).

Os resultados do processamento dos dados de campo (GPR) são as seções de radar (radargramas; figuras 6a, 6b, 6c) para cada um dos perfis executados ao longo das linhas definidas no campo. Utilizando os resultados da interpretação das medidas com o GPR, das informações bibliográficas e as comunicações verbais do responsável pela lavra, chegou-se aos seguintes resultados:

a. O radargrama da linha 1 (figura 6a) mostra nitidamente entre 0 e $30 \mathrm{~m}$ refletores marcantes subhorizontalizados. Entre as distâncias de 30 e $37 \mathrm{~m}$ é possível a identificação de um padrão de reflexão diferente da região anterior, refletores com inclinação contrária e alguns refletores com direção aleatória, indicando a presença do dique. Na profundidade de $90 \mathrm{~m}$ é existe uma suave gradação no padrão das reflexões, possivelmente esta gradação está ligada com a frente de intemperismo do dique.

b. O radargrama da linha 2 (figura $6 \mathrm{~b}$ ) apresenta refletores no interior do quartzito e presença de 2 (dois) diques estreitos, o primeiro entre as distâncias de 7,5 e $12 \mathrm{~m}$, e o segundo entre 21 e $27 \mathrm{~m}$, sendo o primeiro 


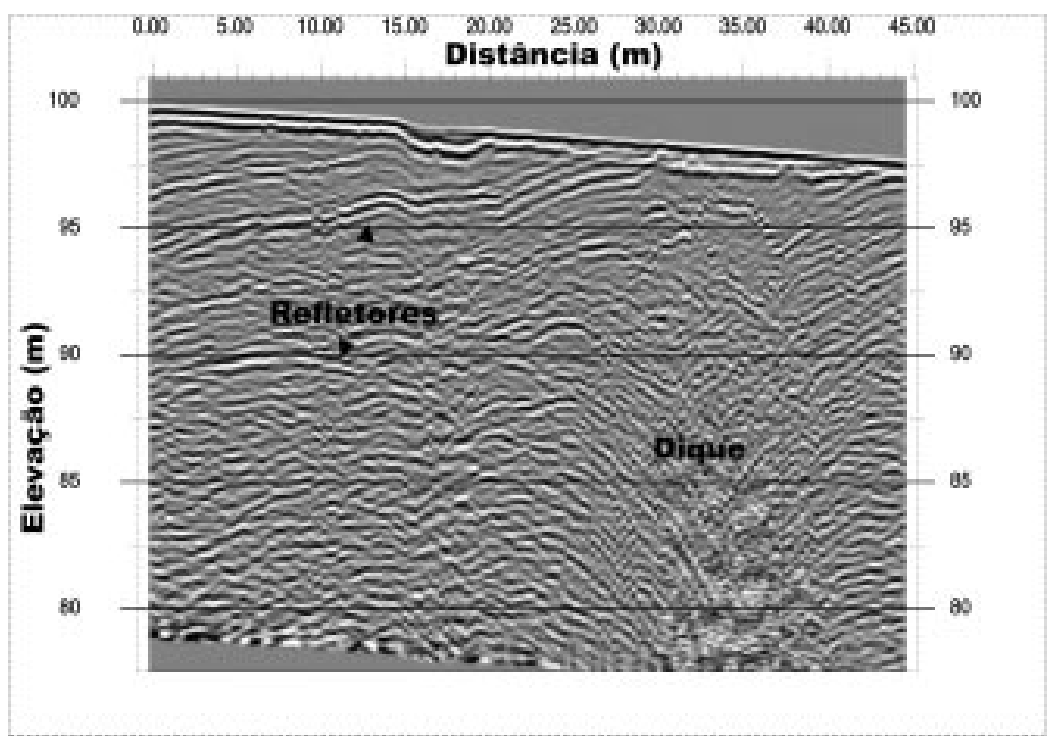

Figura 6a: Perfil 1 obtido com GPR (antena - 50MHz), mostrando a interpretação. Figure 6a: Profile 1 done by GPR (50MHz antennae) and its interpretation.

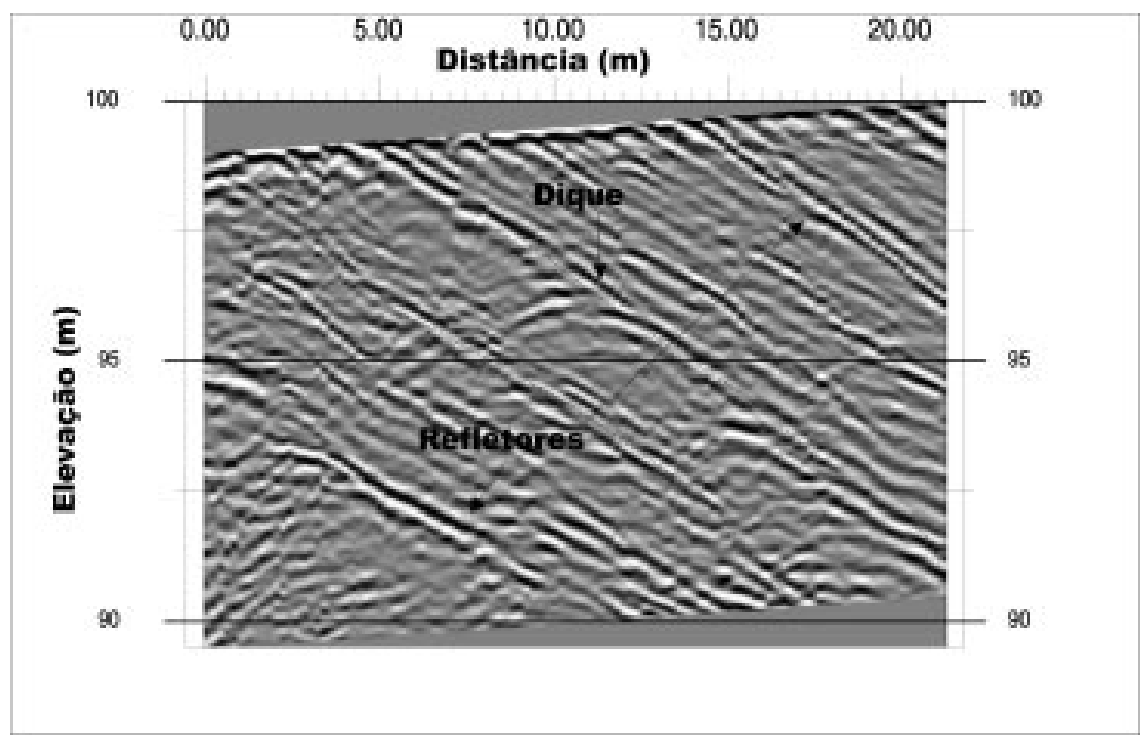

Figura 6b: Radargrama do perfil 2 obtido com GPR (antena - 50MHz), mostrando a interpretação. Figure 6b: Profile 2 done by GPR (5OMHz antennae) and its interpretation.

verticalizado e o segundo inclinado para esquerda. Os refletores no quartzito apresentam inclinação na direção NE.

c. O radargrama da linha 3 (figura 6c), apresenta o dique bem inclinado, distinguindo-se os contatos entre suas paredes e o quartzito. Alguns refletores internos no quartzito estão presentes e podem corresponder a planos de fratura (diáclases), acamamento, com o dique apresentando a mesma atitude, indicando que o magma intrudiu ao longo das estruturas presentes da rocha,podendo ter preenchido mais vias.

d. A intrusão máfica é composta por 3 corpos subparalelos entre si e com uma falha N-S localizado $100-150 \mathrm{~m}$ ao sul.

e. O dique corta indistintamente as unidades quartzíticas das formações Bandeirinha e São João da Chapada, localmente as unidades da Formação Sopa-Brumadinho. f. Os contatos do caulim com as encaixantes são retilíneos ou marcados pela presença de veios de quartzo na interface.

g. A estrutura interna do dique é determinada pelo fraturamento e pela profundidade de alteração:

- Capa espessa de até $10 \mathrm{~m}$ de massa com caulim de pureza variada (branco a vermelho).

- Zona de massa compacta de caulim, óxidos e hidróxidos de Fe/Mn (figura 7) entre 10-20m de profundidade.

- Material nao intemperizado a pouco intemperizado do próprio dique aparecendo nos perfis numa profundidade entre 20 a $30 \mathrm{~m}$.

h. Existem bolsões do dique que invadem os quartzitos \pm paralelo a foliação.

Com relação a formação do caulim, a partir de dados de campo, e daqueles disponíveis na bibliografia, pode- 


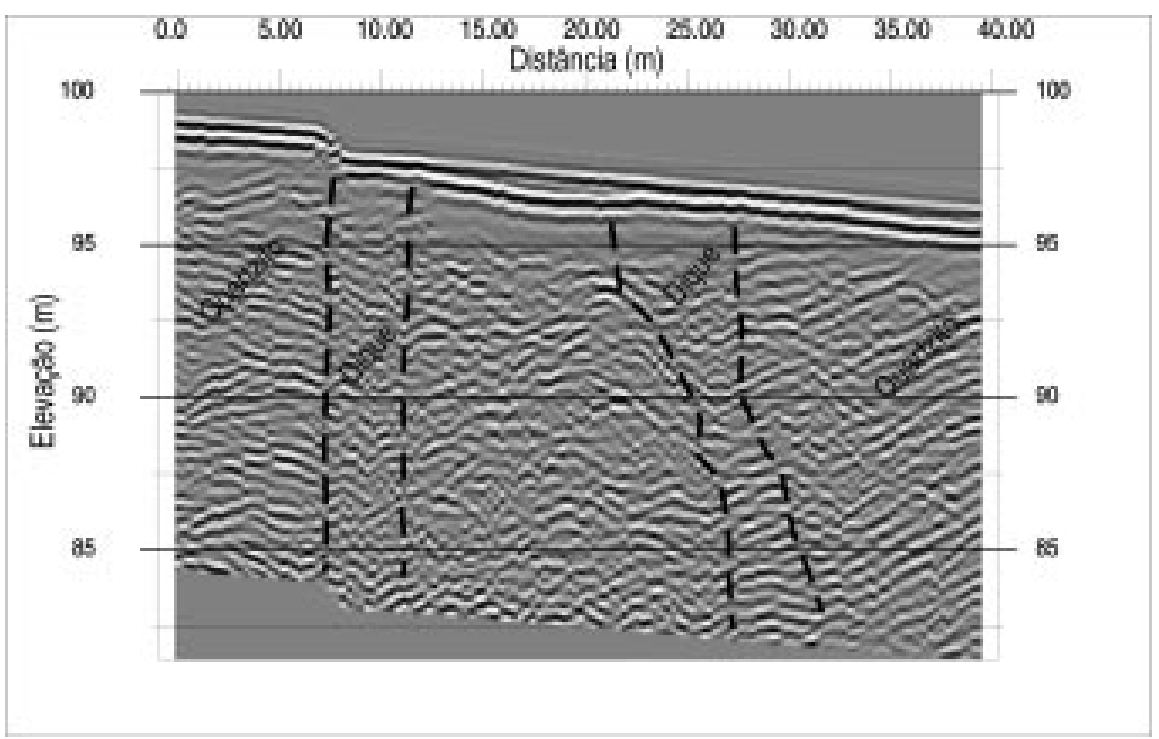

Figura 6c: Radargrama do perfil 3 obtido com GPR (antena de 100MHz), mostrando a interpretação. Figure 6c: Profile 3 done by GPR and its interpretation.

se afirmar:

i. Dados morfológicos dos minerais obtidos por MEV (Sgarbi \& Horn 1992), associados aos novos dados: observações de campo e dados sobre os furos de sonda; indicam para esta ocorrência de caulinita, uma alteração de minerais alumino-silicáticos (especialmente plagioclásio e piroxênio) presentes na rocha original, que se transformam inicialmente em massas ainda com a estrutura original preservada, e após transporte do material dissolvido o progressivo processo de lixiviação proporciona um enriquecimento do material em Caulim/ Óxidos. Sgarbi \& Horn (1992) indicam que este processo leva a deposição final de massas floculares de caulinita. j. A remobilização do ferro da rocha intrusiva está relacionado com o ambiente redutor local (baixo "potencial redox") e com o pH baixo, como consequiência da presença de matéria orgânica (turfa; horizonte orgânico do solo).

k. A retirada do excesso da sílica pode ocorrer em clima quente e pH alcalino associados à existência de boa drenagem local. Processos mais amplos de concentração de alumínio, aliados à retirada mais efetiva de silica, ferro, potássio, etc. em rochas básicas alteradas, tem sido descrito no Espinhaço Meridional (ocorrências de bauxita; conforme Sgarbi \& Horn, 1992).

\section{CONCLUSÕES}

Os trabalhos efetuados (campo; GPR; dados bibliográficos) permitem as seguintes conclusões sobre a intrusão do dique e a sua caulinização e a qualidade do caulim: a. A execução de trabalhos de campo, o mapeamento junto com a interpretação de fotos aéreas permitiu aprofundar os conhecimentos geométricos do corpo (suas delimitações; tipo de contatos; sua orientação e seu mergulho).

b. O método de GPR mostrou a sua aplicabilidade para problemas de depósitos supergênicos, indicando claramente contatos entre as rochas e mostrando variações internas do dique que podem ser interpretados como mudanças de material.

c. Baseado nos dados de campo, nas características do material observado, nos resultados de trabalhos anteriores e na forma geométrica dos corpos observadas nos radargramas (figura 6a), foi sugerido um modelo para a situação atual da estrutura e dos processos em subsuperfície na área do dique e em seu entorno (figura 7).

Para dirimir dúvidas ainda existentes e ampliar o detalhamento da interpretação torna-se necessário a realização de furo de sonda, no ponto de intersecção da linha de GPR com o dique.

\section{AGRADECIMENTOS}

Os autores são gratos ao Instituto de Geociências (IGC), ao Centro de Pesquisa Prof. Manoel Teixeira da Costa CPMTC/IGC/UFMG e ao Centro de Geologia Eschwege em Diamantina (CGE/UFMG) pelo apoio logístico Agradecemos a FAPEMIG pelo apoio financeiro (Projeto CEx-1669-95). Gostaríamos também de agradecer aos colegas que ajudaram na revisão. 


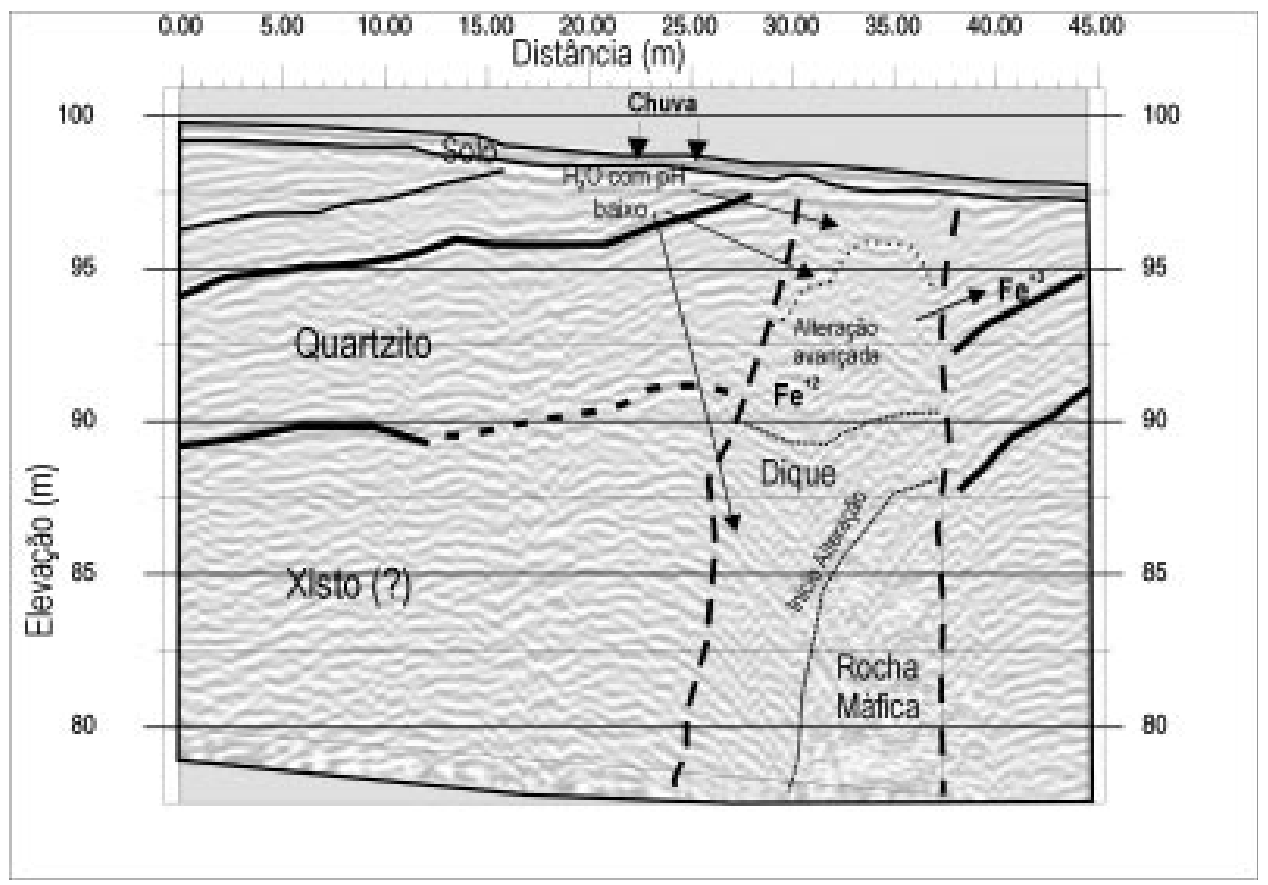

Figura 7: Modelo simplificado da possível situação geológica do intemperismo que causou a formação do caulim. As transformações químicas e os possíveis zoneamentos da alteração estão indicados.

Figura 7: Simplified model of the possible geological situation of the imtemperization which led to the formation of caulim. Indicated are the chemical transformations and the possible zones of the alteration.

\section{REFERÊNCIAS BIBLIOGRÁFICAS}

Aranha, P.R.A.; Augustin, C.H.R.R., Lucio, P.S.; Neves, F.A.P.S. 1998 Estudo das coberturas superficiais na região de Gouveia - MG, com o uso de GPR (Ground Penetrating Radar). In: XL Congresso Brasileiro de Geologia, Belo Horizonte, Seção Poster. CD

Benson, A.K. 1995. Applications of GPR in assessing some geological hazards: examples of ground water contamination, faults, cavities. Journal of Applied Geophysics, 33:177-193.

COMIG. 1997. Projeto Espinhaço. CSR, Belo Horizonte, CD: 2693p.

Daniels, D.J.; Gunton, D.J.; Scott, H.F. 1988. Introduction to subsurface radar. Proceedings of the IEEE, 135(part F, N.4):277-320.

Davis, J.L.; Annan, A.P. 1989. Ground penetrating radar for high resolution mapping of soil and rock stratigraphy. Geophysical Prospecting. 37:531-551.

Grossi-Sad, J.H.; Vaz-De-Melo, M.T. 1969. Recursos econômicos do distrito de Serro, MO. Belo Horizonte. Geologia e Sondagens Geosol/DNPM:1-179.

Guimarães, D. 1933. Os anfibolitos da região diamantifera do norte de Minas Gerais. Anais da Academia Brasileira de Ciências, 5(4) 237-257.

Hara, T.; Sakayama, T. 1985. The applicability of ground probing radar to site investigations. OYO, RP-4159, Tokyo, 32p.

Horn, A.H.; Sgarbi, G.N.C. 1994. Versuch einer Zuordnung von Kaolinproben aus den Bundesstaaten Minas Gerais und espírito Santo zu ihren Ausgangsgesteinen anhand der geochemischen Zusammensetzungen. In: Geowiss. Lateinam., Hannover, Tagungsband: 25 .
Horn, A.H.; Aranha, P.R.A.; Neves, S.C.; Viana Fo L ; Ádamo, R.G. 1998. Novos dados sobre a ocorrência de fosfatos e silicatos de Al-Fe na Serra do Espinhaço Meridional - Perfis nas regiões da Serra da Miúda e Fazenda Formação - Diamantina, Minas Gerais. In: XL Congresso Brasileiro de Geologia, Seção Poster. CD, Belo Horizonte.

Huggenberger,P.; Meier, E.; Pugin, A. 1994. Ground probing radar as a tool for heterogeneity estimation in gravel deposits: advances in data - processing and facies analysis. Journal of Applied Geophysics,31:171-184.

Neves, F.A.P.S.; Aranha, P.R.A.; Lucio, P.S., 1997. Estudos de voçorocas usando GPR. In: Simpósio Regional de Geologia (SBG), Penedo. Resumos. 120p.

Porsani, J.L. 1999."Ground Penetrating Radar" (GPR), proposta metodológica de emprego em estudos geológicos/geotécnicos nas regiões de Rio Claro e Descalvado - SP.Instituto de Geociências e Ciências Exatas, Universidade Estadual de São Paulo,Rio Claro,Tese de Doutoramento, $145 \mathrm{p}$.

Schöll, W.U.; Fogaça, A.C.C. 1981. Projeto mapeamento geológico do Espinhaço Meridional, Quadrículas Guinda/Gouveia. Belo Horizonte, DNPM/UFMG, 44p.

Sgarbi, G.N.C.; Horn, A.H. 1992. Ocorrência de caulinita no Espinhaço, Mg. Bol. Ig-USP, Sér. Cient. 23: 33-42.

Uhlein, A. 1982. Geologia e mineralogia de cromita e itabiritos das mineralizações da região de Serra, MG. Instituto de Geociências/ Universidade de Brasília, Dissertação de Mestrado, Brasília, 189p. 